\title{
The Effect of Personality on Interpersonal Power and Power Distance of Employees of MRF Tyres Ltd. - Kottayam
}

\author{
S. Sasikumar, Sajan M. George
}

\begin{abstract}
Fundamentally every society is made up of individuals and groups who have interaction among them. In the process interaction, power turns out to be the force that keeps the social relationship going. Though there can be various types and levels of interactions, all will have power at the base of it all. Possession of power certainly changes individuals for good or bad. But obviously it happens. Power enables the individuals to make proper decisions provided one is capable of handling power properly. What makes an individual to handle power properly is one's personality. For, it certainly influences the thinking pattern, emotional expressions and deeds. Hierarchy is part and parcel of a society. Here employees with high dominance of power sustain hierarchy. Due to this there occurs opportunities for interpersonal power and power distancing. Power distancing will certainly occur for those employees who find themselves with less power or with more power than the others. Interpersonal power also will occur among the individuals of the society when they are able to influence the other with their positive utilization of power. Here the study that is undertaken with the title the effect of personality on interpersonal power and power distance of employees of MRF Tyre Ltd, Kottayam, is an effort to find the effect of personality on interpersonal power and power distance. It helps to analyze if personality is related to interpersonal power, is there a relationship between personality and power distance and to see if there is any intervention of interpersonal power between personality and power distance. The methodology used will be a descriptive one. Questionnaire and interviews were used to collect data and various statistical tools will be used to analyze the data. Findings are placed after that with a conclusion suggesting to utilize the power for the welfare of the society and its growth.
\end{abstract}

Keywords:--Agreeableness, Conscientiousness, Emotional Stability, Interpersonal Power, Openness, Personality, Power Distance

\section{INTRODUCTION}

Power is a word that is commonly used in today's world. Everyone is interested in having power and in a way it can be said that all crave for power one way or the other. In fact the world is crazy for power and so, one is willing to go to any distance to acquire power. It is evident in professional world, in family life, in one's career and so on. Depending on the way one uses it, success or failure occurs in one's life. When used positively it benefits not only the concerned individual but everyone who is related to it and vice versa too. When one has more power, one has to be more careful in its utilization. Greater the power on has, higher will be the

\footnotetext{
Revised Manuscript Received on December 30, 2019.

S. Sasikumar, Assistant Professor \& Head, Department of Management Studies, Sacred Heart College (Autonomous), Tirupattur, Vellore Dt.- 635 601,Tamil Nadu, India.

Sajan M. George, Research Scholar, Ph. D. Management (full time), Department of Management Studies, Sacred Heart College (Autonomous),
} Tirupattur, Vellore Dt. - 635 601, Tamil Nadu, India power of one's voice in the decision making process. It also helps one to be more involved in the control of the environment. There can be five types of social powers like genuine power which is also known as legitimate power, reward power which is the capacity to give out incentives and compensation to the other, coercive power is the bullying power which makes others scared of being punished and try to do things out of fear and trembling, referent power is the ability of an individual to influence the other though one does not have strictly any power of oneself but because the other likes and appreciates you and expert power is the power that comes to individuals due to one's vast range of knowledge, skill and ability. In general, world sees and acknowledges individuals basing on their power. People are measured to certain extend how much the coworkers view each other and respect each other and how much they are paid for. So here in this article it is an effort to see the effect of personality on interpersonal power and power distance of employees of MRF Tyres Ltd Kottayam.

\section{II.INTERPERSONAL POWER}

Interpersonal power is a power of an individual over another individual as to how much that person is influenced by one. It is basically the capacity of an individual to influence the thought pattern, behavior and action of another. Another way of saying, it the cause of change that happens in the behavior of another. This influence can be due to a promised reward or it can be because something is withheld. Either way this power can be exercised. A promised reward can be due to the fulfillment of a set target and withholding of it can be due to the unaccomplishment of an expected target

\section{III.POWER DISTANCE}

Power distance is as the term has it, is a process where less powerful keep themselves away from the more powerful one. It can be a distancing done by employees from the management. Here the basic underlining factor is that there is a common trend of distribution of power unequally between individuals. So it is an acceptance of inequality. A less powered person automatically feels happy to distance oneself from the greater powered person. In a social hierarchy power distance is the strength. It is actually the lower graded individuals accepting the greater power of the higher graded individuals of the society.

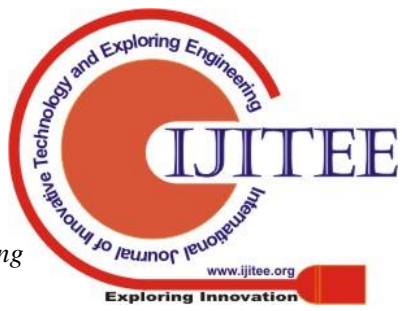




\section{The Effect of Personality on Interpersonal Power and Power Distance of Employees of MRF Tyres Ltd. - Kottayam}

Greater the power distance in the society, bigger the inequality among the individuals and vice versa. When society has lower power distance individuals find themselves in a better position to interact with each other. In a county where power distance is greater, one with much power will be looked up to and shown greater respect and honor and the opposite is expected if the country has only lesser power distance.

\section{IV.PERSONALITY}

Personality is that which defines an individual. It is one's character, the way one behaves, one's emotional and intellectual patterns that makes an individual the way one is. It is developed from one's family, society and environment. Generally personality is expected to be stable. Personality also includes the moods that one undergoes, the attitudes one possess and the opinions one has which gets clearly expressed in the way one interacts with the other in the society. Personality has characteristics which are inborn as well as those that have been acquired in one's life. And this is what distinguishes one from the other. The expression of this is found in the way one talks, walks, expresses one's needs and wants and conducts oneself in the society.

\section{V.LITERATURE REVIEW}

Aminu Yusuf Dikko and Co., in their article 'Moderating Role of Power Distance on Personality towards Affective Commitment of Lecturers in Nigeria', state that personality and power distance has a significant relationship. The power distance factor has a crucial role to play in the building up of the hierarchy of the society. They go on to say that it strongly affects the commitment of the people towards the roles that they have to play in the society. Article concludes by saying in order to ensure a healthy society, retention tactics with stable work force is to be ensured. This only will enable the voice of the voiceless to be heard in the society.

In the article titled 'Power Distance and its Moderating Role in the Relationship between Situational Job Characteristics and Job Satisfaction: An Empirical Analysis Using Different Cultural Measures' Sven Hauff\& Nicole Frranziska Richter, comments that power distance is a matter of national culture for that is what affects the confirmation and acceptance of work and the related position and prestige. They

also go on to say that those companies who have employees from various cultures will have to take this into consideration to give job satisfaction to the employees.

Henry K. Y. Fock, et.al., write in their article titled 'Moderation Effects of Power Distance on the Relationship between types of Empowerment and Employee Satisfaction', empowerment of employees are good but still power distance has to be maintained in order to keep the efficiency of the organization going. It also says that if the society has big disparity in power, then in the organization, there is no use of trying to bring in empowerment of the employees for it does not bring any felt desired changes in the employees. So the article goes on to state that social and psychological empowerment is good for society where power distance is moderate or minimal.
In 'Culture and Concepts of Power', Carlos and Sharon describe about the need for conceptualizing power. They go on to say that culture states whatever is to be done with power and what is meaningful with the same. Here they also talk about vertical individualism which is more with regard to personalized power and on horizontal collectivism which is more for the growth of the society. Vertical individualism they also state that it is for personal growth and development whereas horizontal collectivism is more for the growth and development of the society collectively. It also states that these factors form and develop the attitudes of individuals to live well in the society.

Joel B.Bennett, write in his article 'Power and Influence as Distinct Personality Traits: Development and Validation of a Psychometric Measure', there is always a need for power and a feeling of ego going along for position. Along with this, wanting to influence and the desire to persuade others affect the entire society.

\section{VI.OBJECTIVES OF THE STUDY}

- To study the effect of personality on interpersonal power and power distance of the employees of MRF Tyres Ltd., Kottayam

- To identify the relationship between personality and power distance of the managers and staff of the organization

- To know the effect of personality on interpersonal power of the employees

- To find out if interpersonal power intervenes between personality and power distance

- To study the effect of interpersonal power on power distance of the employees of the organization

\section{VII.HYPOTHESIS}

Ho : There is significant relationship between personality and power distance

Ho : There is a significant relationship between personality and interpersonal power

Ho : Interpersonal power significantly intervenes between personality and power distance

Ho :There is a significant relationship between interpersonal power and power distance

\section{VIII.RESEARCH METHODOLOGY}

Following are the points that were given prime importance.

Source of Data: Primary data is collected from the company itself and the secondary source of data are from the website, journals and books.

Study Period: The period of study extends to two months and fifteen days only.

Analytical Tools: Various analytical tools have been used to get the best outcome like One Way ANOVA, Regression Analysis, Sobel Test, Correlation and Frequency. 


\section{ANALYSIS AND FINDINGS\& RESULTS}

01. Relationship between personality and power distance through one way ANOVA test

\begin{tabular}{|c|l|l|c|c|c|}
\hline Variable & \multicolumn{1}{|c|}{ Personality Trait } & Mean & Std. Deviation & F & P \\
\hline \multirow{5}{*}{ Power Distance } & Openness & 21.42 & 2.07 & & \\
\cline { 2 - 6 } & Conscientiousness & 20.00 & 2.73 & & \\
\cline { 2 - 6 } & Extraversion & 19.50 & 0.71 & & \\
\cline { 2 - 6 } & Agreeableness & 23.18 & 2.68 & & \\
\cline { 2 - 6 } & Emotional Stability & 26.00 & 0.00 & & \\
\hline
\end{tabular}

Here the calculated value F (4.146) is significant. That is to say there is a significant relationshipbetween personality and power distance.

02. Effect of personality on interpersonal power through one way ANOVA test

\begin{tabular}{|c|l|c|c|c|c|}
\hline Variable & Personality Trait & Mean & Std. Deviation & F & P \\
\hline \multirow{4}{*}{$\begin{array}{c}\text { Interpersonal } \\
\text { Power }\end{array}$} & Openness & 39.67 & 3.73 & & \\
\cline { 2 - 6 } & Conscientiousness & 40.63 & 4.27 & & .340 \\
\cline { 2 - 6 } & Extraversion & 39.50 & 9.19 & & \\
\cline { 2 - 6 } & Agreeableness & 38.73 & 2.97 & & \\
\cline { 2 - 6 } & Emotional Stability & 41.00 & 1.41 & & \\
\hline
\end{tabular}

Here the mean score does not differ with personality trait. So the conclusion is that there is no significant relationshipbetween personality trait and interpersonal power.

03. If interpersonal power intervenes between personality and power distance (I. P. - P. - P. D.) through Regression analysis and Sobel test

\begin{tabular}{|c|c|c|c|c|c|}
\hline I. P. - P. - P. D. & & Value & Se & $\mathbf{t}$ & $\mathbf{P}$ \\
\hline \multirow{6}{*}{ Openness } & $\mathrm{a}=\mathrm{bmx}$ & .6341 & .2711 & 2.3389 & .0255 \\
\hline & $\mathrm{b}=\mathrm{bym} \cdot \mathrm{x}$ & .2212 & .1365 & 1.6207 & .1149 \\
\hline & $\mathrm{c}=$ byx & -.1188 & .2177 & -.5459 & .5888 \\
\hline & $\mathrm{c}=$ byx.m & -.2591 & .2295 & -1.1290 & .2673 \\
\hline & Indirect effect & .1402 & .1116 & 1.2568 & .2088 \\
\hline & \multicolumn{3}{|l|}{ Sobel test } & 1.332 & 0.183 \\
\hline \multirow{6}{*}{ Conscientiousness } & $\mathrm{a}=\mathrm{bmx}$ & .7035 & .2803 & 2.5102 & .0171 \\
\hline & $\mathrm{b}=$ bym.x & .0840 & .1362 & .6165 & .5419 \\
\hline & $\mathrm{c}=$ byx & .4060 & .2173 & 1.8688 & .0706 \\
\hline & $\mathrm{c}=$ byx.m & .3470 & .2394 & 1.4494 & .1569 \\
\hline & Indirect effect & .0591 & .1058 & .5583 & .5766 \\
\hline & \multicolumn{3}{|l|}{ Sobel test } & 0.599 & 0.549 \\
\hline \multirow{6}{*}{ Agreeableness } & $a=b m x$ & .2395 & .2423 & .9885 & .3301 \\
\hline & $\mathrm{b}=\mathrm{bym} \cdot \mathrm{x}$ & .1031 & .1149 & .8976 & .3761 \\
\hline & $\mathrm{c}=$ byx & .5240 & .1594 & 3.2865 & .0024 \\
\hline & $\mathrm{c}=$ byx.m & .4993 & .1622 & 3.0771 & .0043 \\
\hline & Indirect effect & .2347 & .0464 & .5319 & .5948 \\
\hline & \multicolumn{3}{|l|}{ Sobel test } & 0.664 & 0.506 \\
\hline \multirow{6}{*}{ Emotional Stability } & $\mathrm{a}=\mathrm{bmx}$ & .1145 & .2922 & .3919 & .6976 \\
\hline & $\mathrm{b}=\mathrm{bym} \cdot \mathrm{x}$ & .1391 & .1132 & 1.2290 & .2280 \\
\hline & $\mathrm{c}=$ byx & .6089 & .1914 & 3.1818 & .0032 \\
\hline & $\mathrm{c}=$ byx.m & .5930 & .1904 & 3.1152 & .0039 \\
\hline & Indirect effect & .0159 & .0540 & .2951 & .7679 \\
\hline & \multicolumn{3}{|l|}{ Sobel test } & 0.373 & 0.709 \\
\hline
\end{tabular}

Since Sobel test is not found to be significant, it is understood that interpersonal powerdoes not intervenebetween personality and power distance. 
The Effect of Personality on Interpersonal Power and Power Distance of Employees of MRF Tyres Ltd. Kottayam

\section{Effect of interpersonal power on power distance (I. P. - P. D.) through Correlation}

\begin{tabular}{|c|c|c|c|c|c|}
\hline Variables & Correlation & Lower Bound & Upper Bound & $\mathbf{Z}$ & $\mathbf{p}$ \\
\hline I. P. - P. D. & 0.218 & 0.173 & 0.263 & 3.206 & 0.002 \\
\hline
\end{tabular}

From the above analysis it has been identified that there is no significant relationshipinterpersonal power on power distance.

\section{CONCLUSION}

It is a universal fact that power is everywhere and normally in a society it is mainly with the top level of the society which could be more precisely with the top hierarchy. Individuals certainly can acquire power either by looking for it, or by virtue of the office that one holds. It has to be used with utmost care to see that the society benefits out of it. It has been also found from the research that there is a significant relationship between personality and power distance. And the other factors like relationship between personality trait and interpersonal power are hardly significant. It is also understood that interpersonal power does not intervene between personality and power distance. And finally there is no significant relationship of interpersonal power on power distance. So it has to be noted that there has to be effort made to improve the personality in order to keep less distance between the powerful and the less powered ones to work in close collaboration to make the organization progress. Here let me close it with a little thought from Plato who said, power is to be put into good use for the organization, community and the country at large.

\section{REFERENCES}

1. J. P. Guilford, Personality (Delhi: Surjeet Publications, 2007).

2. Uma Sekaran\& Roger Bougie, Research Methods for Business: A Skill Building Approach, Fifth Edition, (Wiley India (P) Ltd, 443536/7, Ansari Road, Daryaganj, New Delhi - 02, 2012).

3. Aminu Yusuf Dikko, et.al., "Moderating Role of Power Distance on Personality towards Affective Commitment of Lecturers in Nigeria", International Journal of Management Research \& Review (IJMMR), Volume 7, Issue 2, 2017, pp. 82-98.

4. Carlos J. Torelli\& Sharon Shavitt, 'Culture and Concepts of Power', Journal of Personality and Social Psychology, Vol. 99, No. 4, 2010, pp. 703-723.

5. Henry K. Y. Fock, et. al., "Moderation Effects of Power Distance on the Relationship between types of Empowerment and Employee Satisfaction", Journal of Cross-Cultural Psychology, 44 (2), 2013, pp. 281-298.

6. Joel B. Bennett, 'Power and Influence as Distinct Personality Traits: Development and Validation of a Psychometric Measure', Journal of Research in Personality, Volume 22, Issue 3, 1988, pp. 361-394.

7. Sven Hauff\& Nicole Frranziska Richter, 'Power Distance and its Moderating Role in the Relationship between Situational Job Characteristics and Job Satisfaction: An Empirical Analysis Using Different Cultural Measures', Cross-Cultural Management An International Journal, 22 (1), 2015, pp. 68-89.

8. https://study.com/academy/lesson/hofstedes-power-distancedefinition-examples-quiz.html

9. https://www.apa.org/topics/personality/

10. https://www.britannica.com/topic/personality

11. https://www.encyclopedia.com/social-sciences/encyclopediasalmanacs-transcripts-and-maps/ interpersonal-power 